\title{
EDITORIAL
}

\section{Associate Editor for Reviews and Book Notes}

$\mathrm{M}$ any of us have found ourselves at the receiving end of negative reviews and know well what an unpleasant experience that can be. It is especially painful when we feel that the review's author has misrepresented or misunderstood our writings, or has chosen to focus on a small portion of a larger work while not addressing what we see as its major themes and concerns. When individuals are asked to review a book for American Antiquity, it is my expectation that they will bring their expertise on a topic or region to critically and fairly evaluate the book that they have been asked to discuss. A good review highlights what individual reviewers perceive to be a work's major strengths and weaknesses. And we hope that reviewers will clearly distinguish a work's minor editorial problems from more serious substantive issues. (I freely confess that when editing reviews-which almost always exceed requested word limits-more often than not I delete such critiques as "Figure 3.1 was missing a scale," or "there were several typographical errors," unless reviewers indicate that such problems are both pervasive and have a serious negative impact on the publication.)

American Antiquity seeks to review a very wide range of books on a wide range of topics beyond the expertise of any review editor. This makes "fact checking" of reviews difficult (especially once the books have been mailed to reviewers and are no longer in the editor's possession). I therefore always ask each reviewer to send a copy of their completed review to the book's senior author or editor as a courtesy and to allow authors the opportunity to respond directly to reviewers before publication (sometimes resulting in minor or major revisions by reviewers). Less-than-glowing reviews may (and often do) still rankle, but a critical review that is well argued and carefully presented can effectively highlight theoretical and interpretive debates and raise important substantive questions.

Throughout my tenure as review editor of American Antiquity, I have tried to avoid publishing reviews that did not adhere to these expectations, although admittedly have not always succeeded. The (fortunately very few) problematic reviews that have arrived in this office have often involved individuals (reviewers and authors) who had a "history" that I was unaware of or who were rehearsing old disagreements familiar to cognoscenti but beyond my ability to evaluate. It has been my experience that highly negative reviews often, although certainly not always, have such a subtext (something that readers should perhaps consider when reading reviews).

The April 1999 issue (Vol. 64, No. 2) contained a review of William Keegan's book, Bahamian Archaeology, written by Charles Hoffman. Both author and reviewer feel strongly about their perspectives, and both are certainly entitled to disagree with the other's views. I will not go into the details of their disagreements here. Professor Keegan has prepared a detailed rebuttal to the review 
that I am sure he will be willing to make available directly to interested readers. Although I am not qualified to assess their substantive disagreements, I have taken the unusual step of placing a comment here because I acknowledge that as review editor, I fell down on the job in this case. Given the strong negative tone of this review, I should have taken on the extra work of "fact checking" and communicating with both author and reviewer (and to be fair, the reviewer himself did suggest this), and of ensuring that the review focused on "big picture" issues, rather than more less substantive critiques. I apologize to Professor Keegan and the readership for failing to do so.

Ultimately, any review presents one reader's opinion of a work, and other readers will undoubtedly have very different perspectives and reactions. The best result of this unfortunate experience would be for interested readers to read the book themselves and form their own opinion.

CARLA M. Sinopoli 